\title{
Domain Restriction and the Arguments of Quantificational Determiners
}

\author{
Anastasia Giannakidou \\ University of Chicago
}

\section{Introduction}

Classical generalized quantifier (GQ) theory posits that quantificational determiners (Q-dets) combine with a nominal argument of type $e t$, a first order predicate, to form a GQ. In a recent paper, Matthewson (2001) challenges this position by arguing that the domain of a Q-det is not of type $e t$, but $e$, an entity. In this paper, I defend the classical GQ view, and argue that the data that motivated Matthewson's revision actually suggest that the domain set can, and indeed in certain languages must, be contextually restricted overtly.

First, I show that the central predictions of Matthewson's proposal are too strong. The core facts are then reconsidered in the light of the hypothesis that what looks like $e$-formation is in fact an operation of domain restriction on the nominal argument. The implication of this analysis is that languages vary with respect to whether they overtly encode contextual restriction in the QP: languages like St'át'imcets Salish do, but languages like English resort to an implicit or covert strategy (and may allow overt restriction of a particular type only on occasion). This conclusion presents a refinement of what Neale (1990) and von Fintel (1998) call the 'explicit' strategy of contextual restriction, i.e. the claim that domain restriction is always encoded syntactically (for recent variants see Martí 2001, Stanley 2002, Stanley and Szabó 2000).

What I will be showing here suggests that it matters whether a language implements restriction overtly or covertly, and where it is implemented: on the nominal argument, or on the Q-det itself. Most significantly, the specific choice will have consequences for the determiner system itself. In the overt strategy language types, Q-dets will always operate on restricted nominal domains-but in covert or implicit strategy languages there will be room for Q-dets that are not restricted, in agreement with what is observed in the literature (e.g. Cooper 1996, von Fintel 1998 and references therein). Typically, weak indefinite-like Q-dets, e.g. (modified) numerals, and Q-dets like few, many, several, etc. have been argued to not be contextually restricted the way strong Q-dets like every and each are. We would not expect to find such cases in St'át'imcets Salish-or if we do, we would expect a different syntactic pattern to arise.

The impact of this distinction carries over to non-quantificational DPs, i.e. what would be the corresponding definite and indefinite DPs of the form the NP and $a N P$ in a language like English. In an overt strategy language like St'át'imcets Salish where determiners must combine with overtly restricted nominal arguments, the distinction between definites and indefinites will be rendered superfluous: because they will always refer to a contextually salient set of individuals, in this state of affairs, definites as well as indefinites will be 
referential; hence there will be no need to morphologically mark the distinction between the two forms. St'át'imcets Salish non-quantification DPs are then both definite and indefinite, a fact that captures consistently the behavior described in Matthewson (1999), specifically their seemingly exceptional property of being always existentially closed at the highest level.

Systematic resort to the covert strategy, on the other hand, can render the very use of a Q-det itself superfluous. This is, I will speculate, what we observe in languages where no definite or indefinite article are employed (e.g. Chinese, Russian), where a bare nominal can be both definite or indefinite; but I will not look at such languages in more detail at the present stage.

The discussion proceeds as follows. In section 2 , I discuss the data that motivated Matthewson's 2001 proposal. In section 3, I present what I see as the major problems with that proposal. In section $4 \mathrm{I}$ argue for an alternative analysis of the DP as encoding contextual restriction leaving the NP type unaffected. I then show how this account explains the seemingly peculiar SS facts without giving up the idea that the domain of a Q-det is a predicate. In section 5 we discuss the issue of nominal restriction versus Q-det restriction in English and Greek, and reexamine the exceptional behavior of DPs in Salish in the light of our analysis.

\section{The structure of QPs in the St'át'imcets Salish DP}

Matthewson 2001 argues that quantification in natural language proceeds in two steps: first, a determiner D creates a sum of type $e$ out of the NP denotation; this object then serves as the argument of the Q-det to form a generalized quantifier. The claim draws on an investigation of QP structures in St'át'imcets Salish (SS). The basic features of QP structures in SS that are of relevance here are the following (Matthweson 1999, 2001):

a. There is no distinction between a definite and an indefinite D; only one D is used: $i \ldots a$ (for plural), and $t i \ldots a$ for singular, referred to as $X \ldots a$.

b. As independent arguments, DPs are existentially closed at the highest level. This yields translations of them as definites as well as indefinites:

$$
\text { q'wez-ílc [ti-smúlhats-a] ' }\{\text { The/a }\} \text { woman danced.' }
$$

Matthewson 2001: ex. (3a).

The wide scope property is further illustrated in the example below:

$$
\text { qus-en-ítas [i n7án'was-a smém'lhats] [i kalhélhs-a míxalh] }
$$
shot.tr.3pl.erg. det two(hum.)-det woman(dim.) det three.det bear Two girls shot three bears. (Matthweson 1999: (29))

OK: A total of two girls shot a total of three bears. (= The two girls shot the three bears). \# Each of two girls shot three bears, s.t. the total number of bears shot was six.' 
'Narrow' scope is missing here for the DP corresponding to 'three bears', and the two DPs are interpreted as definites with equivalent seemingly 'wide' scopes.

c. DPs are never used as predicate nominals (Matthweson 2001: (6)), which suggests that they are always interpreted in type $e$.

d. There are no English-style partitive structures with a partitive preposition.

e. In the typical case, the complement of the Q-det is a DP rather than NP:

(3) a tákem [i smelhmúlhats-a $]$

all DET womam(PL)-DET

b [QP Q-DET [ $\left[_{D P} D\left[_{N P} N\right]\right]$

f. Weak QPs appear in variable position: either to the left, or to the right of $\mathrm{D}$ (as is, crucially, the case in (2), a point to which we return).

We will focus initially on the structures in (3) following Matthewson 2001; but, obviously, we can reach a actual explanation only if the analysis of this structure makes the other properties of the determiner system follow.

The discontinuous D $X \ldots a$ creates DPs that are definite or indefinite, as indicated by (1), but Mathewson chooses to treat it as an indefinite determiner, creating a DP that is interpreted as a choice function, with a special property: it must be existentially closed at the highest level only. This property, which sets SS DPs apart from 'regular' indefinites, unfortunately is merely stipulated in Matthewson 1999; why SS DPs, unlike 'regular' indefinites, exhibit this exclusive preference remains unexplained. In essence, the top-closure requirement translates into a claim that the DP denotes a contextually salient choice function, which in effect would render it equivalent to a referential DP, indeed a definite (or, a singleton indefinite in the sense of Schwarzchild 2002). This will be the line I will pursue later, in the discussion in section 5.

The $\mathrm{D}$ occurring in (3) is argued to function as an operator yielding an $e$ type individual. It combines with the predicate and returns one of the atomic or plural individuals that satisfy the predicate:

$$
\llbracket X \ldots a_{k} \rrbracket^{g}=\lambda f \in D_{\text {et }}(g(k))(f)
$$

(Matthweson 2001: (18))

The index of the determiner specifies which choice function will be used; $g$ is an assignment function, from indices to choice functions, thus $g(k)$ is a choice function of type et,e. If the DP is plural, a pluralization operator * is posited with standard semantics: it takes an one-place predicate of individuals $f$ and returns all the plural individuals composed of members of the extension of $f$.

II ${ }^{*} \rrbracket$ is a function from $\mathrm{D}_{e t}$ into $\mathrm{D}_{e t}$ such that, for any $\mathrm{f} \in \mathrm{D}_{\mathrm{et}}, \mathrm{x}: \mathrm{D}_{\mathrm{e}}:[* \mathrm{*}]$ $(\mathrm{x})=1$ iff $[\mathrm{f}(\mathrm{x}) \neq 1 \wedge \exists \mathrm{y} \exists \mathrm{z}[\mathrm{x}=\mathrm{y}+\mathrm{z} \wedge[*(\mathrm{f})](\mathrm{y})=1 \wedge[*(\mathrm{f})](\mathrm{z})=1]]$ (Matthweson 2001: (17)) 


$$
\llbracket \text { s smelhmúlhats (pl.) } \rrbracket=\llbracket * \rrbracket(\llbracket \text { smúlhats (sg.) } \mathbb{D} \text { ‘women’ }
$$

The determiner then combines with the pluralized $\mathbf{N}$ and received the interpretation indicated. The choice function analysis is equivalent to the more familiar one of the definite article using uniqueness and maximality:

$$
\begin{array}{ll}
\text { a. } & \text { [ the } N P \rrbracket=\max (\llbracket N P \mathbb{D} \\
\text { b. } & \max (P)=x[x \in P \wedge \forall y[y \in P \rightarrow y \leq x]]
\end{array}
$$

This function will give the unique atomic individual that satisfies NP if the NP is singular, and the maximal sum of NP, i.e. the sum of all members of NP, if the NP is plural. Thus, the SS determiner $X \ldots a$ really works like a definite determiner in forming a maximal sum individual. A supporting fact for this conclusion is that the created DP has indeed the exhaustive interpretation predicted by the maximal sum: $\boldsymbol{i}$ smelhmúlhats-a never picks out a non-maximal sum of (contextually salient) women.

Based on the obligatoriness of DP, (3b) is proposed as the structure of QPs in SS. Matthewson then makes the stronger claim that this is how quantification is done crosslinguistically. This challenges the standard GQ view that Q-Dets combine with $e t$ arguments, and it has a number of undesirable consequences.

\section{Problems with the assumption that the nominal argument is type $e$}

What I see as a fundamental conceptual problem with the account I just described is that it falls short of connecting the basic characteristics of the SS determiner system that we described. We would like to know, for example, why a language with the QP structure in (3) does not exhibit the definite/indefinite distinction. We do not want these two properties to be linked just by accident or stipulation. We also want to know why such a language does not allow overt partitives, why weak quantifiers have variable positions, and ultimately, why English-like languages do not have the properties of SS.

Given the conclusions reached in both papers by Matthewson, a related question at this fundamental level is why the Salish DP has the distinctive property of always being interpreted in type $e$. This is a property very much unlike DP elements in languages like English, where definites and indefinites freely type-shift to quantificational $(e t, t)$ or predicative types $(e t)$, shifts that have been well-described and understood since Partee's (1987) important work. The SS DP appears to defy the basic characteristics of the class it is supposed to belong to-and it may well turn out that there exists indeed this special kind of indefinite. But before such a conclusion is reached, and in order for it not to be merely a stipulation $^{1}$, it is pertinent to address the question of whether SS DPs type- shift, and if not, why not. Addressing this question becomes particularly pressing given that within Partee's system there is a natural map between individuals and predicates, i.e. sets containing them. I will actually propose an analysis along this 
line in section 5; but first, I want to point out some specific empirical problems of Matthewson's proposal.

\subsection{Incompatibility of $Q$-dets with definites}

Since the sum operator in English, and the languages that look like it, is the definite article, it is predicted that Q-dets in these languages should be able to combine directly with definites. But, as is well known, this is not borne out: though all (and only) can combine with definites (recall the English (3a), the bulk of Q-dets doesn't. I illustrate below with English and Greek:
a. *every the boy; *most the boys; *few the boys; *three the boys
b. all the boys; only the boys
a. $\quad *$ kathe to aghori; *merika ta aghoria; *tria ta aghoria 'every the boy; several the boys; three the boys'
b. ola *(ta) aghoria; mono ta aghoria
(Greek) 'all the boys; only the boys'

Why Q-dets in English and Greek do not combine with definites, and the related question of why inserting the partitive of yields well-formedness (three of the boys, most of the boys), remain unexplained. Worse, we are forced to say that elements that we have reasons to believe are not determiners- like all (Brisson 1997) and only (von Fintel 1997) - exhibit the typical case, which is at best counterintuitive. (Notice that the Greek determiner oli 'all' in fact requires the definite determiner, a point to which we return.).

\subsection{Vacuity of partitive 'of'}

Since Q-dets combine directly with $e$-objects, we are forced to treat partitive of as semantically vacuous, contra Ladusaw 1982, where of is inserted to ensure that Q-det receives an argument of type et:

$$
\llbracket \text { of } N P \rrbracket=g(a) \text { if } \llbracket N P \rrbracket=I_{a} \text {; undefined otherwise. }
$$

In this formula, from Ladusaw 1982, $g$ is a 'consists of' function which takes any group-level individual and returns the set of atoms corresponding to the generator set. Of the women is thus the same type of object as women, but instead of denoting the set of all women it denotes the set of all contextually relevant women. We will see that this analysis of of is very close to my own view of the role of $X \ldots a$, thus rendering the SS QP structure equivalent to a partitive. This explains why there are no partivive structures of the English type in SS.

Matthewson argues instead that of is inserted only for case reasons. $O f$, however, can be optional: all (of) the boys, half (of) the boys, both (of) the boys, quite unexpectedly if it is there for case only. Moreover, we leave unaccounted for certain well-known facts about partitives (among others, contrasts like half of the water vs. *one of the water (de Hoop 1997) which are not expected to exist). 
Also not expected to exist is the obligatoriness of the definite article with the Greek oli 'all' that I mentioned earlier.

\subsection{Episodic occurrences of 'most' and contrast with 'all'}

Two predictions are made about all and most occurring with bare NPs. First, it is predicted that these structures will be only kind-denoting, because it is only the kind that gives the right $e$ input. Second, since bare most and all combine with kind-denoting bare plurals, it is also predicted that languages which do not allow kind denotation for their bare plurals, will also not allow all/most with a bare NP argument. Both predictions are problematic.

Though it seems correct to say that all NP does not receive episodic or existential meanings, the parallel breaks down with most, which routinely admits episodic interpretations with bare NPs:

(11) a. Most women at yesterday's meeting were professors.

b. *All women at yesterday's meeting were professors.

Von Fintel 1998 gives a similar example with bare most:

(12) On our school trip, almost everyone stayed up late on the first night. The next morning, as was to be expected, the teachers were at the bus on time, but most students arrived late.

Unmodified most students in the episodic example above is clearly existential. Matthewson acknowledges the problem of episodic interpretation of most; the contrast with all in (11), at the same time, is also quite unexpected.

The problem becomes more acute when we consider the respective Greek determiners: the definite D $i$ preceding the NP cannot be dropped with oli "all", but it can with $i$ perissoteri, lit. the.pl more, the complex determiner meaning 'most', allowing both generic and episodic interpretations in both cases. Notice, also, in (13b) that English most, unlike all, is incompatible with a definite:

a. $\quad$ oli i fitites 'all the students'; *oli fitites 'all students'

b. $\quad i$ perissoteri i fitites '*most the students'; (lit. the more the students)

c. i perissoteri fitites 'most students'

(14) a. I perissoteri (i) fitites doulevoun sklira.

Most students work (imperfective) hard. (generic)

b. I perissoteri (i) fitites efigan noris.

Most students left (perfective) early. $\quad \cdot \quad$ (episodic)

Greek marks a perfective vs. imperfective distinction on the verb, hence the examples above are unambiguously episodic and generic/habitual, respectively. The crucial example is (14a): Greek and English most students/i perissoteri fitites are generic, but Greek bare plurals, unlike English, are not generic. This questions the 
prediction that languages lacking generic bare plurals will not combine their most Q-dets with a bare plural.

\subsection{Variable position of $Q$-det with respect to the definite}

In Matthewson's analysis the DP is the complement of Q-det. But once we move to other determiners, or look at other languages, we see that we also have evidence for embedding a Q-det under a D. This is, for example, the case of the Greek $i$ perissoteri 'most' that we just discussed. Likewise, the Greek determiner meaning 'each' involves embedding of the quantifier 'every' under the definite article (Giannakidou 1998):

o kathe, lit. the.masc.sg every; $i$ kathe, lit. the.fem.sg every; to kathe, lit. the.neut.sg 'each'

I will suggest (section 5) that the definite $\mathrm{D} o$ composes directly with the Q-det, to form a complex Q-det. Interestingly, o kathe is further incompatible with a definite, contrasting with i perissoteri 'most':

$$
\begin{aligned}
& \text { a *o kathe } 0 \text { fititis '*each the student' } \\
& \text { b } i \text { perissoteri } \boldsymbol{i} \text { fitites '*most the students'; } \\
& \text { i perissoteri fitites 'most students' }
\end{aligned}
$$

We revisit these facts in section 5; in my proposal, they suggest an operation of restricting the Q-det itself and not its nominal argument-a point to consider against Stanley's (2002) thesis that domain restriction is always nominal restriction. It is worth emphasizing that Matthweson also presents [D QP] orders: with the weak quantifiers which receive the 'wide scope' readings we mentioned earlier (recall example (2)):

$\begin{array}{ll}\text { i } \quad \text { kalhélhs-a } & \text { míxalh } \\ \text { det.pl. three (anim).det } & \text { bear } \\ \text { Translated as: three bears } & \end{array}$

But examples are also given indicating that a strong determiner can be embedded under D, like the one below (Matthewson 2001: (41c)):

$$
\begin{aligned}
& \text { i } \quad \text { zí7zeg'-a } \quad \text { sk'wemk'úk'wm'it } \\
& \text { det.pl each-det } \quad \text { child.pl } \quad \text { (gloss from Matthewson 2001) } \\
& \text { Translated as: each child }
\end{aligned}
$$

This order is very parallel to that of Greek $o$ kathe. Interestingly, this seems to be a more general crosslinguistic pattern: e.g. it is observed also in Basque, where strong Q-dets (and not their nominal arguments) typically compose with D (see data in Etxeberria Otaegi 2004). Crucially, D composing with Q-det is obligatory for strong Q-dets but excluded with weak quantifiers. I will not explore more 
details in this paper, but it is worth emphasizing that there is substantial crosslinguistic evidence for an operation of D attaching to the Q-det rather than to the nominal, a fact unexpected in Matthewson's (or Stanley's 2002) account.

In Greek and SS, the result of D QP is a strong distributive quantifier, which like English each, but unlike all and oli, is incompatible with collective predicates (see also Matthewson 1999: 101-103):
a. $\quad *$ To kathe pedi sigentrothike.
'* Each child gathered.'
b. Ola ta pedia sigentrothikan.
'All the children gathered.'

Moreover, o kathe, each, and possibly also i zí7zeg'-a, are presuppositional, or veridical (Giannakidou 1998) in that they presuppose a nonempty domain ${ }^{2}$ :

(Non)veridicality of determiners

A determiner $\delta$ is veridical w.r.t. its NP argument iff it holds that:

$\llbracket \delta \mathrm{NP} V \mathrm{VP} \rrbracket_{\mathrm{c}}=1 \rightarrow \llbracket \mathrm{NP}_{\mathrm{c}} \neq \varnothing$; otherwise, $\delta$ is nonveridical.

This property of each/kathe explains why they cannot be used generically (Beghelli and Stowell 1997), and why they do not license polarity items (PIs):

(21) a. * Each student who bought anything reported to the Dean.

b. $\quad$ Every student/all students $\}$ who bought anything reported to the Dean.

For the Greek data and more on this issue, see discussion in Giannakidou 1998, 1999. The crucial point is that each has often been thought of as being definitelike in English too, in exhibiting properties like presuppositionality or D-linking (as opposed to all, which is typically the opposite).

Clearly, we want to correlate the D-QP embedding to the property of veridicality (which requires a nonempty domain), and distributivity. Likewise, in the case of weak quantifiers, where both embeddings D QP and Q DP are allowed, we should be able to establish what the difference is in the produced meanings. As I have alluded to earlier, the Q-DP order is arguably a partitive; the $\mathrm{D}-\mathrm{QP}$, then, is plausibly a strong, definite meaning-a hypothesis consistent with the property of the D-QP construal to take the highest scope. In Matthewson's account, these pieces of the puzzle remain unconnected.

From the discussion in this section it seems fair to conclude that we have not seen substantial evidence for a need to revise our theory of quantification so that Q-dets crosslinguistically combine with $e$ rather than $e$ arguments. In fact we saw that, if we do adopt this revision, a number of relatively well-understood data become problematic.

Next, I will propose an alternative analysis that maintains the classical GQ structure, offering, at the same time, a perspective to explain the distinctive features of SS, and the core facts presented here, in a consistent way. 


\section{The alternative: DP as a supplying contextual restriction}

Instead of altering the type of the NP argument of Q-dets, I will take the SS data to suggest that Q-dets in this language combine with a nominal argument that must be first contextually restricted (see some comments in Matthewson 2001: section 3.1 to this effect), and that contextual restriction is done overtly, via D. I am going to argue further that the contextually restricted DP undergoes predicative type-shift under Q-det.

My idea follows much contemporary work (Partee 1989, von Fintel 1994, 1998, Stanley 2002, Stanley and Szabó 2000, Martí 2002) in assuming that the domains of Q-dets are contextually restricted by covert domain variables at LF in, e.g., English (but see also Recanati 1996 and Breheny 2003). (These variables are usually free, but they can also be bound, though I will not consider binding here). The covert variables can be either atomic, e.g. $C$, or complex of the form $f(x)$, corresponding to selection functions (von Fintel 1994: 31, 1998, Stanley 2002, Stanley and Szabó 2000, Martí 2002):

(22) In my semantics class, every student passed the exam.

(23) a $\forall \mathrm{x}$ [student $\mathrm{f}_{\mathrm{f}(\mathrm{x})}$ ] passed the exam.

b $\quad \forall \mathrm{x}$ [student $\mathrm{c}_{\mathrm{c}}$ ] passed the exam.

In these examples, the nominal argument of $\forall$, student, is not the set of students in the universe, but the set of students in my semantics class. This is achieved by positing the domain variable $\mathrm{C}$, which will refer to a contextually salient property, in this particular case the property of being in Anastasia's semantics class. This property then will intersect with the property student, and the product will be the (desired) set of students in Anastasia's semantics class. In the complex version $f(x)$, the domain variable consists of a free function variable and an argumental variable or type $e$ (that can be bound). Relative to a context $c, f$ maps $e$ to $e t$, i.e. an object to a set, producing intersecting semantics. So, [student $\mathrm{f}_{\mathrm{f}(\mathrm{x})}$ ] in the example above will be interpreted as:

$$
\llbracket\left[\text { student }_{\mathrm{f}(\mathrm{x})}\right] \rrbracket=\llbracket \text { student } \rrbracket \cap\{\mathrm{x}: \mathrm{x} \in \mathrm{c}(\mathrm{f})(\mathrm{c}(\mathrm{i}))\} \quad(\text { Stanley 2002: (9)) }
$$

This set is, then, the nominal argument of the Q-det 'every' in (22). Stanley (2002) further argues that the domain variable is part of the nominal argument, and not of the Q-det itself, contrasting with Martí (2002) who composes the variable with the Q-det:

$$
\text { no student }=[\text { no } \mathrm{f}(\mathrm{x})](\text { student })
$$

(Martí 2002: 5: (19))

The bulk of quantifier structures seem to support Stanley's model; however, we also saw evidence for Q-det itself composing with D-recall $o$ kathe, $i$ zí7zeg'-a, and the Basque data involving strong Q-dets discussed in 
Etxeberria Otaegi (2004), which can be taken to exhibit variants of structures like (25), an option Stanley 2002 argues against. Crosslinguistically, it seems, we must allow for both options - nominal as well as determiner restriction.

The idea that QPs are contextually restricted combine with two other important premises: (a) Westerstahl's (1985) idea that the definite article introduces a context set, which is another way of capturing the familiarity property of definites; and (b) that definite descriptions undergo predicative shift, e.g. when they are used as predicate nominals:
a Bill is the pilot.
b Bill and John are our top candidates.

The proper analysis of the DPs the pilot, and our top candidates (which, incidentally, is a morphological definite in Greek, as possessives are in general: $i$ kaliteri ipopsifii) must assign to them type et (for a recent discussion see Graff 2002). The shift from the referential or quantificational type to the predicative one is a manifestation of type-shifting in the sense of Partee 1987. Crucially, if we combine the context set/familiarity idea with the predicative analysis of definites, we produce a meaning for the definite in which it denotes a contextually restricted set of individuals. As Schwarzchild (2002) suggests, indefinites can also be contextualized in a similar fashion in certain contexts, and when this happens, they become like definites in terms of familiarity. This premise will be important when we consider again the SS data in 5.2.

In Salish, I will propose, the single D that the language employs embodies familiarity, and contributes the contextual $C$ variable. This means that when $D$ combines with NP, the result is a GQ meaning that contains a contextually specified set of individuals as its generator:

$$
\begin{aligned}
& \llbracket \mathrm{X} \ldots \mathrm{a} \rrbracket=\lambda \mathrm{C} \lambda \mathrm{P} \lambda \mathrm{Q}\{\mathrm{x}: \mathrm{C}(\mathrm{x})=1 \& \mathrm{P}(\mathrm{x})=1\} \subseteq\{\mathrm{x}: \mathrm{Q}(\mathrm{x})=1\} \\
& \llbracket \text { ti smúlhats-a } \rrbracket=\lambda C \lambda \mathrm{P}\{\mathrm{x}: \mathrm{C}(\mathrm{x})=1 \& \operatorname{woman}(\mathrm{x})=1\} \subseteq\{\mathrm{x}: \mathrm{P}(\mathrm{x})=1\} \\
& \text { 'D woman' }
\end{aligned}
$$

This makes the DP look very much like a definite. The domain $\mathrm{Q}\{\mathrm{x}: \mathrm{C}(\mathrm{x})=1$ \& woman $(x)=1$ \} is a contextually salient set, in this case a singleton containing an atomic contextually specified individual that meets the description 'woman'; or it may be a set comprising a contextually salient complex individual, if the DP combines with a plural NP, just like with a plural definite.

In order for the DP quantifier to combine with the Q-det, we must assume that it undergoes type shifting. Partee 1987 postulates shifts to et from either a GQ meaning (by applying BE), or a referential meaning (by applying Id). Given that the SS contains a generator, we might want to identify $X \ldots a$ as a definite, as suggested in earlier work by Matthewson, or merely trivialize the question of whether it is a definite or an indefinite:

$$
\begin{aligned}
& \text { a. } \mathrm{BE}: \mathrm{GQ}(e t, t) \rightarrow e t: \lambda \mathrm{P}_{\mathrm{et}, \mathrm{t}} \lambda \mathrm{x}[\{\mathrm{x}\} \in \mathrm{P}] \\
& \text { b. } \mathrm{Id}: e \rightarrow e t: \operatorname{Id}(\mathrm{x})=\lambda \mathrm{x}[\mathrm{x} \leq \mathrm{y}], \text { or } \lambda \mathrm{x}[\mathrm{x}=\mathrm{y}] \text { if } \mathrm{x} \text { is a singularity }
\end{aligned}
$$


The above are Partee's BE and Id operations, both yielding predicative types. BE is taken to be the shift from the GQ meaning of the indefinite article, typically; it applies to a GQ, finds the singletons that are contained in it, and collects their elements in a set. Id, on the other hand, is the inverse of the $t$ operator, i.e. the typical case of the definite. Id 'undoes' what the $\imath$ did, via the part- of (for plurals), or identity relation (for singulars), as indicated above. Intensional versions of these operations can also be defined, as in Chierchia 1998. The bottomline is, $X \ldots a$, just like definites or indefinites, can be taken to undergo either BE or Id, hence resulting in a set interpretation in either case.

If we assume, quite standardly, that type shifters are indeed syntactic creatures, then we have to say that in SS, the type shifter is covert. So the actual structure of our original (3) is not (3b), but the following:

$$
\left[\mathrm{QP}_{\mathrm{QP}} \mathrm{Q}-\mathrm{DET}\left[_{\mathrm{PP}} \varnothing\left[_{\mathrm{DP}} \mathrm{D}\left[\left[_{\mathrm{NP}} \mathrm{N}\right]\right]\right]\right]\right.
$$

The type shifter is a null preposition, e.g. a null counterpart of the English partitive of. Hence the typical SS QP structure is really a partitive. Hence, assuming that $\mathrm{D}$ performs domain restriction on the nominal, and that the DP subsequently undergoes predicate shift enables the classical GQ analysis in SS.

But, then, aren't we predicting that English and Greek DPs would be able to do the same thing and conbine directly with Q-dets? The answer is negative. In the context of Chierchia (1998), where the use of an overt type-shifter blocks the use of a covert one, it follows that overt of will block the covert shift in languages employing partitive prepositions, and these languages will not let their Q-dets combine directly with definites. SS lacks an overt of, and it is this fact that allows the covert shifter in the QP.

I will close with cosnidering an alternative way of looking at the relation between D and NP. We can argue that the two do not compose via saturation, but via restrict in the sense of Chung and Ladusaw (2003), positing a rule like the following:

$$
\text { Restrict }([\lambda \mathrm{x} \mathrm{NP}(\mathrm{x})], \mathrm{C})=\lambda \mathrm{x} \mathrm{NP}(\mathrm{x}) \wedge \mathrm{C}(\mathrm{x})
$$

D contributes $\mathrm{C}$; the operation leaves the original NP type unaffected by treating the DP as an intersective modifier supplying a context set. Similarly, we can maintain that the DP remains a predicate and combines with the noun via predicate modification (as in Heim and Kratzer 1998). In these approaches, as in Westerstahl (1985), D is truly syntactically ambiguous between a quantifier type and a modifier one. This option, however, is less preferable to the type-shifting account I proposed here, because it can only stipulate the empirical contrast between English/Greek and SS that we just explained. 


\section{Implications}

\subsection{Nominal restriction or $Q$-det restriction? We need both!}

So, what is the basic difference between English and Greek, on the one hand, and SS, on the other? Clearly, what I proposed so far provides evidence in support of Stanley's position that domain restriction affects the nominal argument of the Qdet. In SS, nominal restriction is obligatory via D; but in English and Greek style languages, nominal restriction happens covertly, or overtly with partitive of. This predicts correctly that direct embedding of DP under Q-det in English/Greek will not be possible. At the same time, however, we must allow restriction of the Qdet too, in order to capture [D QP], and the fact that D may attach to Q-dets crosslinguistically.

In particular, the Greek case $o$ kathe seems to provide evidence for the option of domain restricting the Q-det itself:

$$
\begin{aligned}
& \text { a. } \quad\left[{ }_{\mathrm{QP}} o_{\mathrm{D}}+\text { kathe }_{\mathrm{Q}-\mathrm{DET}}\left[{ }_{\mathrm{NP}} \text { fititis }_{\mathrm{N}}\right]\right] \\
& \text { b. o kathe fititis }=[\text { kathe }(C)] \text { (student) 'each student' } \\
& \text { c. } \quad \text { Io kathe } \rrbracket=\lambda C \lambda \mathrm{P} \lambda \mathrm{Q}\{\mathrm{x}: \mathrm{C}(\mathrm{x})=1 \& \mathrm{P}(\mathrm{x})=1\} \subseteq\{\mathrm{x}: \mathrm{Q}(\mathrm{x})=1\} \\
& \text { 'each' }
\end{aligned}
$$

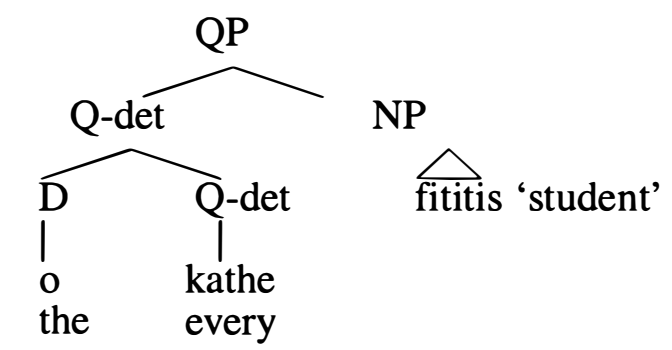

(32a) suggests that $o$ kathe is a complex determiner, and we can view this as incorporation of D to Q-det, as indicated (perhaps D having moved from a lower NP internal position, or directly adjoining to Q-det). Hence, domain restriction of the determiner yields a new determiner which contains the additional variable $\mathrm{C}$ and is thus contextually restricted. It seems plausible to extend this analysis to SS $i$ zí7zeg'-a, each, and possibly also to the strong Basque Q-dets, as discussed in Etxeberria Otaegi (2004). This structure denotation is consistent with the veridicality property of the Greek determiner, and the common observation that each is like a definite. It is plausible, however, that veridicality doesn't apply in all cases, given, for example, that all strong Q-dets in Basque are D-restricted (while it remains to be established whether they are all veridical).

The option of restricting the Q-det can also be invoked for embedding numerals and weak quantifiers under D:

the three boys; the many problems with this idea; the few students 
In all cases, the result is QPs that are domain restricted: they refer to contextually specified sets of three boys, many problems with this idea, and few students. Crucially, a further definite embedding is not possible:

*the three the boys; *the many the problems with this idea; *the few the students; *each the boys

So, if domain restriction happens at the determiner level, the addition of an extra definite yields a type mismatch: Q-det would receive $e$ rather than $e t$ argument. Notice that the use of overt of is also excluded: *the three of the boys, suggesting that restriction happens only once.

Let us look now at two residual cases. The first one concerns oli 'all', whose exceptional basic properties are that (a) it must compose with the a definite DP (unlike other Q-dets), and (b) it is incompatible with partitive apo 'of':

$$
\text { * oli apo tus fitites ' all (of) the students'. }
$$

To explain this, we may want to say that the DP argument of oli did undergo predicate shift and is already a predicate; hence apo is redundant. But such reasoning makes oli exceptional, given the general pattern of Greek or English Ds which do not predicate shift on their own under Q-det. To avoid such an exception, and following Brisson 1997, we can deny the status of oli as Q-det, and treat the remaining structure as a DP (thus rendering apo insertion redundant).

The second case is Greek i perissoteri 'most' which exhibits the D QP order while at the same time optionally allowing a definite argument: $i$ perissoteri fitites. This option, which is admittedly more marked that the canonical version without the embedded definite, suggests the following structure:

$$
\left[{ }_{\mathrm{DP}} i_{\mathrm{D}} \quad\left[\mathrm{QP} \text { perissoteri } i_{\mathrm{Q}-\mathrm{det}}\left[{ }_{\mathrm{DP}} i_{\mathrm{D}}\left[\mathrm{NP} \text { fitites }{ }_{\mathrm{N}}\right] 1\right]\right]\right.
$$

I perissoteri i fitites is thus a DP constituent (unlike $o$ kathe); the use of the lower definite can be seen as a case of definite reduplication which is overwhelming in Greek (e.g. o kalos o fititis, lit. 'the good the student'):

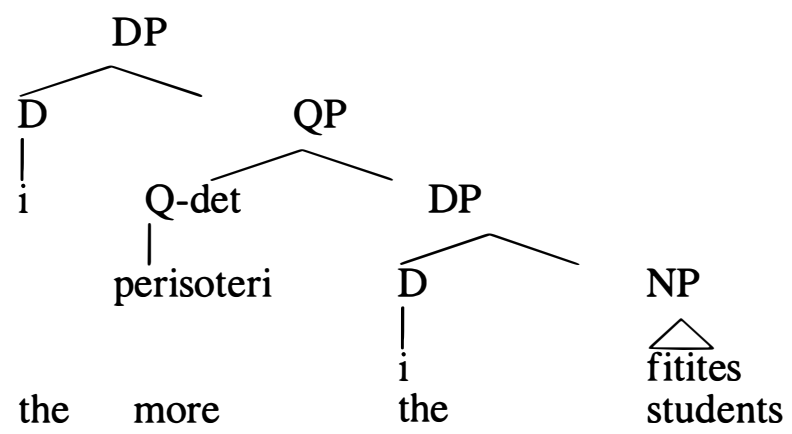

(In the case of $i$ perisoteri fitites, of course, the complement of Q-det is the expected NP).Why is reduplication not allowed with $o$ kathe? Obviously, because 
o kathe NP is not a DP; since reduplication only happens with definites, we do not expect it with o kathe.

In sum, we see that the overt option of domain restricting via $D$ is occasionally also available in languages that exploit the implicit (covert) strategy. Crucially, in these languages D-restriction applies at the level of the Q-det, and not at the nominal, since overt nominal restriction is taken care by of.

\subsection{Back to the 'special' properties of Salish}

We are now ready to consider how our analysis makes the basic properties of the SS determiner system, which remained previously unconnected, follow. Recall:
a. There is no distinction between a definite and an indefinite determiner.
b. As independent arguments, DPs are existentially closed at the highest level only.
c. There are no English-style partivive structures.
d. Weak QPs appear in variable position: either to the left or to the right of D.
e. The typical structure of QPs embeds a DP under Q-det.

So far, the assumption that DPs under Q-det in SS denote contextually restricted sets has explained the following. First, we capture the absence of partitive of in SS (point c). Second, we capture the variable position of D with respect to $Q$ (point d) as a function of whether we restrict the nominal or the Q-det itself: the [Q DP] order gives a contextually restricted D that will be strong and possibly also veridical. With weak quantifiers, our two results combined yield partitive meanings for the [Weak-Q DP] structures, and definite-like meanings for [D Weak-Q] ones.

Let us now consider the final challenge: how does the proposal that DPs in SS denote contextually salient sets capture the absence of definite/indefinite distinction in SS, and the fact that DPs are always closed at the highest level? It is not hard to see. In our account, DPs, like all SS QPs refer to contextually salient (sets of) individuals. I repeat from section 4:

$$
\llbracket \mathrm{X} \ldots \mathrm{a} \rrbracket=\lambda \mathrm{C} \lambda \mathrm{P} \lambda \mathrm{Q}\{\mathrm{x}: \mathrm{C}(\mathrm{x})=1 \& \mathrm{P}(\mathrm{x})=1\} \subseteq\{\mathrm{x}: \mathrm{Q}(\mathrm{x})=1\}
$$

The domain set $\{\mathrm{x}: \mathrm{C}(\mathrm{x})=1 \& \mathrm{P}(\mathrm{x})=1\}$ can be viewed uniformly as a singleton containing an atomic contextually specified individual (if $\mathrm{D}$ is combined with a singular NP), or a complex individual (if combined with a plural). This means that the DPs have GQ denotations identical to that of definites. In effect, then, the definite versus indefinite distinction is neutralized in SS, because all DPs have unique contextually specified generators.

Interestingly, in languages like English, the common ground of a context can narrow down the domain of an indefinite to merely a singleton set (Schwarzchild 2002), yielding the 'specific' indefinite meaning. When this happens, the indefinite 'acquires' the familiarity of a definite, with the ensuing 
impression of ultra-wide scope (which need not involve movement at all). Putting all this together, we can explain why SS DPs are always bound at the highest level: in a language where D always contributes a context set, DPs end up denoting existential quantifiers that have unique generators. In such a language there will be no need to distinguish morphologically definites from indefinites since whatever is DP will always be referential.

\section{Conclusion}

The proposal that $\mathrm{D}$ in SS provides nominal domain restriction, combined with a covert type-shifter, was shown to enable the classical GQ analysis for Salish. Unlike the earlier account of Matthewson $(1999,2001)$, this analysis also explains the basic properties of QP structures in a non-stipulative way.

I will conclude with two brief remarks on the more general consequences of what was proposed. Matthewson 2001 argued against the position that SS DPs are definites. What I am proposing here can be refined into a claim that SS DPs are ambiguous between a definite meaning (which always contains a generator set), and an indefinite, which may do so if the context assigns to it a singleton domain. It may also turn out that SS DPs are indefinites that systematically exhibit the singleton domain pattern, in which case, as I said, they are rendered 'definite' like.

Finally, Matthewson's (1999) account of SS DPs as wide scope choice function indefinites was intended as an argument for a particular implementation of the choice function analysis-one that does not allow intermediate readings (Kratzer 1998). However, in the context of what I suggested here, there is no need to appeal to a choice function analysis after all. Hence it is hard to see how the SS facts can have a bearing on the debate of which implementation of the choice function analysis is preferable-and, indeed, they appear to provide no argument for, or against, a choice function, or an indefinite analysis, as such.

\section{Endnotes}

* I am grateful to Lisa Matthewson for her extensive comments which helped me a lot in further clarifying the relevant properties of St'át'imcets Salish, and my own views of how to handle them. Many thanks also to the SALT 14 reviewers and audience as well as Donka Farkas, Jack Hoeksema, Luisa Martí, Jason Merchant, Gianluca Storto, and Urtzi Etxeberria Otaegi for comments and discussion. Thanks to Urtzi also for bringing the Basque data to my attention.

${ }^{1}$ The point against 'special' items features prominently in the recent literature on polarity items (PIs; see, e.g., Giannakidou 1998, 2001 and references therein). Composition external stipulations that posit particular scopings for PIs without appeal to their lexical-semantic content, though popular in the earlier polarity tradition, became disfavored in the later 90's, where the task has been to establish why PIs are subject to the particular scopings there are. Matthewson's 1999 
discussion, in emphasizing the special character of SS DPs without addressing the question of why, echoes this earlier tradition.

${ }^{2}$ Notice that being a veridical QP does not entail widest scope. In particular, when interacting with similarly presuppositional QPs, each receives what appears to be narrow scope, as in Each boy saw the two movies, which is true only in case there are two movies $x$ such that $x$ were watched by each boy $y$. Likewise with the scope permutations we noted in example (2).

\section{References}

Beghelli, Filippo and Tim Stowell: 1997, 'Distributivity and Negation: the Syntax of each and every', in Anna Szabolcsi (ed.), Ways of Scope Taking, 71-197, Kluwer.

Breheny, Richard. 2003. A lexical account of implicit (bound) contextual dependence. In SALT 13.

Brisson, Christine. 1997. On Definite Plural NPs and the Meaning of all. Proceedings off SALT VII.

Chierchia, Gennaro. 1998. Reference to kinds across languages. Natural Language Semantics 6: 339-405.

Chung, Sandra, and William A. Ladusaw. 2003. Predication and Saturation. MIT Press.

Cooper, Robin. 1996. The role of situations in generalized quantifiers. In Shalom Lappin (ed.), The Handbook of Contemporary Semantic Theory, Blackwell. 65-86.

Etxeberria Otaegi, Urtzi. 2004. Do all quantifiers behave the same way compositionally? Ms. University of the Basque Country and LEHIA.

Von Fintel, Kai. 1994. Restrictions on Quantifier Domains. PhD thesis, UMass, Amherst.

Von Fintel, Kai. 1997. Bare plurals, bare conditionals, and only. Journal of Semantics 14: 1-56.

Von Fintel, Kai. 1998. The semantics and pragmatics of quantifier domains. Ms.MIT.

Giannakidou, Anastasia. 1998. Polarity Sensitivity as Nonveridical Dependency. John Benjamins.

Giannakidou, Anastasia. 1999. Affective dependencies. Linguistics and Philosophy 22: 367-421.

Heim, Irene, and Angelika Kratzer. 1998. Semantics in Generative Grammar. Blackwell.

de Hoop, Helen. 1997. A semantic reanalysis of the partitive constraint. Lingua 103: 151-174.

Kratzer, Angelika. 1998. Scope or pseudoscope? Are there wide scope indefinites? In S. Rothstein (ed.) Events and Grammar, Kluwer, Dordrecht. 163-196.

Ladusaw, William, A. 1982. Semantic constraints on the English partitive construction. In D. Flickinger, et al. (eds.) Proceedings of WCCFL 1. 231242. 
Matthewson, Lisa. 1999. On the interpretation of wide scope indefinites. Natural Language Semantics 7: 79-134.

Matthewson, Lisa. 2001. Quantification and the nature of crosslinguistic variation. Natural Language Semantics 9: 145-189.

Martí, Maria Luisa. 2002. Contextual variables. PhD thesis. University of Connecticut.

Neale, Stephen. 1990. Descriptions. MIT Press.

Partee, Barbara. 1987. Noun Phrase interpretation and type-shifting principles. In P. Portner and B. Partee (eds), Formal semantics: the Essential readings, Blackwell Oxford. 357-381.

Recanati, Francois. 1996. Domains of discourse. Linguistics and Philosophy 19: 445-475.

Schwarzchild, Roger. 2002. Singleton indefinites. Journal of Semantics 19: 289314.

Stanley, Jason. 2002. Nominal restriction. In Logical Form and Language, ed. by G. Peters and G. Preyer, 365-388. Ocford University Press.

Stanley, Jason, and Zoltan Szabó. 2000. On quantifier domain restriction. Mind and Language 15:219-261.

Westerstahl, Dag. 1984. Determiners and context sets. In J. van Benthem and A. ter Meulen (eds), Generalized quantifiers in Natural Language, Foris, Dordrecht. 45-71. 